\title{
Estimating the impacts of urban planning concepts on reducing urban sprawl using certain spatial indicators
}

\author{
Bolormaa Batsuuri ${ }^{1}$, Christine Fürst ${ }^{2}$, Buyandelger Myagmarsuren ${ }^{3}$ \\ ${ }^{1}$ Department of Geography, School of Arts and Sciences, National University of Mongolia, Ulaanbaatar 14200, \\ Mongolia; bolor_8315@yahoo.com \\ ${ }^{2}$ Institute for Geosciences and Geography, Dept. Sustainable Landscape Development Martin Luther University Halle- \\ Wittenberg; christine.fuerst@geo.uni-halle.de \\ ${ }^{3}$ Department of Land Management, School of Agroecology, Mongolian University of Life Sciences, Ulaanbaatar \\ 17024, Mongolia; buya_city@yahoo.com \\ *Correspondence: bolor_8315@yahoo.com
}

\begin{abstract}
Numerous cities in our modern world are unfortunately encountering the negative effects of urban sprawl: this includes unrestricted settlement, degradation in the quality of their environment, traffic congestion, substandard buildings, and air pollution as well as flooding, swampy areas, landslides, and settlement zones with dilapidated utilities and infrastructures that are not safe for living. The Ulaanbaatar City land management master plan defined the settlement zone area suitable for living as 33,698 hectares. However, due to unrestricted urban sprawl caused by exponential growth of the city's population, the settlement zone area reached 39,235 hectares, which exceeds the limit by 5,537 hectares. In order to tackle this issue, several urban planning concepts were developed to be implemented within the Ulaanbaatar City urban planning framework. It is, in any case, problematic to choose a single planning concept due to the fact that neither measurements nor analyses are being made of the respective spatial quantitative indicators in urban planning assumptions that are taking the current situation into consideration. One of the prerequisites for identifying an optimal concept in urban planning is an assessment of the current situation, and measuring the impacts against its quantitative data. In the current research, when defining Ulaanbaatar city sprawl, the base year was selected as 1990, the time when the city started to sprawl. Research analyses were made using geographic information systems based on the satellite data 1990, 1995, 2000, 2005 Landsat TM-5, 2010 Quickbird, 2015 World View and 2020 Sentinel2, respectively. Based on the results of determining the city sprawl using spatial indicators, the urban planning concepts applied thus far have been analyzed in relation to land use efficiency and land use struct u ral changes. This research paper addresses the issue of reducing unrestricted urban sprawl by increasing the internal density of the city. The research results show that, by applying the concept of a compact city in urban redevelopment planning for 4,604 hectares, and by allocating the settlements in 12,479 hectares, it is possible to reduce the urban expansion threefold and increase land use efficiency accordingly.
\end{abstract}

\section{Keywords}

Urban planning, Land management, Urban sprawl, Spatial analysis

\section{Introduction}

One of the most serious problems in the 21 st century is global population growth and consequent urban expansion, particularly in developing countries [1]. Such a trend for developing countries has emerged in Mongolia since the 1990s in relation to the country's shift from a centrally planned to a market oriented economy [2]. The Ulaanbaatar City urban development process until the middle of the last century evolved in a unique way considering the specifics of the nomadic civilization. The first scientifically-based urban development master plan was developed in 1954 at "Gypragor" Institute in Moscow, where it has been revised 6 times since then. With over a decade of social transition until the 5th Master plan was developed in 2002, land utilization was basically managed without any planning or 
general policy [3]. This situation established the foundation for today's uncontrolled urban expansion [4]. Unrestricted settlement and rapid growth in urban populations caused by uncontrolled sprawl is causing a number of problems in urban land use [5]. Urban development concepts aimed at reducing such uncontrolled urban sprawl are being implemented without much results, hence this sprawl, which is estimated to reach approximately 60,000 hectares by 2040 [6], has been increasing every year. As of today, Ulaanbaatar City urban planning has been applying a combination of monocentric, polycentric and compact city concepts, but in the future only one optimum concept is to be identified and implemented. Therefore, the purpose of the research at hand is to estimate and analyze the impact of urban planning concepts by identifying Ulaanbaatar City's uncontrolled sprawl using spatial indicators and comparisons of land use form and land use efficiency quantitative data. The research has the following objectives:

1. Study the current situation of Ulaanbaatar City's uncontrolled sprawl starting in $\mathbf{1 9 9 0}$ and identify its coverage;

2. Analyze the impact of different urban development concepts applied in Ulaanbaatar City's master plan in relation to urban sprawl by using spatial indicators; and

3. Analyze the impact of uncontrolled urban sprawl on the city's general form by comparing and integrating the indicators for each urban planning concept.

\section{Methods and Data}

\subsection{Study area}

To achieve the aim of the research, Ulaanbaatar, the capital city of Mongolia, and its urban sprawl are used as an example. Ulaanbaatar has been growing significantly since the midtwentieth century and has been considered the country's main urbanized area since then [7]. Ulaanbaatar city is located in the center of Mongolia, in the southern edge of Khentii mountain range, surrounded by mountains from four sides in the valley along the river basin. Hence, it has limited area suitable for settlement. The city total area comprises 470,440 hectares. The city's main part is located along the banks of Tuul River, which originates in the Khentii mountain range at an elevation on average of $1,350 \mathrm{~m}$ above sea level. Most of residential areas stretch out along the northern section of the river. According to the Ulaanbaatar City land management plan, the zone suitable for settlement should be an area of 33,698 hectares. This was identified using the following 8 factors:

- Slope of the land, with an incline of less than 15 degrees

- Not on permafrost

- Outside of forest and river protection zones

- Not in the National park area

- Not in croplands

- Not swampy

- Not in the zone prone to the risks of flooding or rock falls on the mountain slope

- Not in the area under engineering limitations or restrictions [8].

Moreover, a total of 15,403 hectares of land in the eastern part of Ulaanbaatar was planned for a new settlement zone, however due to its distance from the city center this area was not developed. 


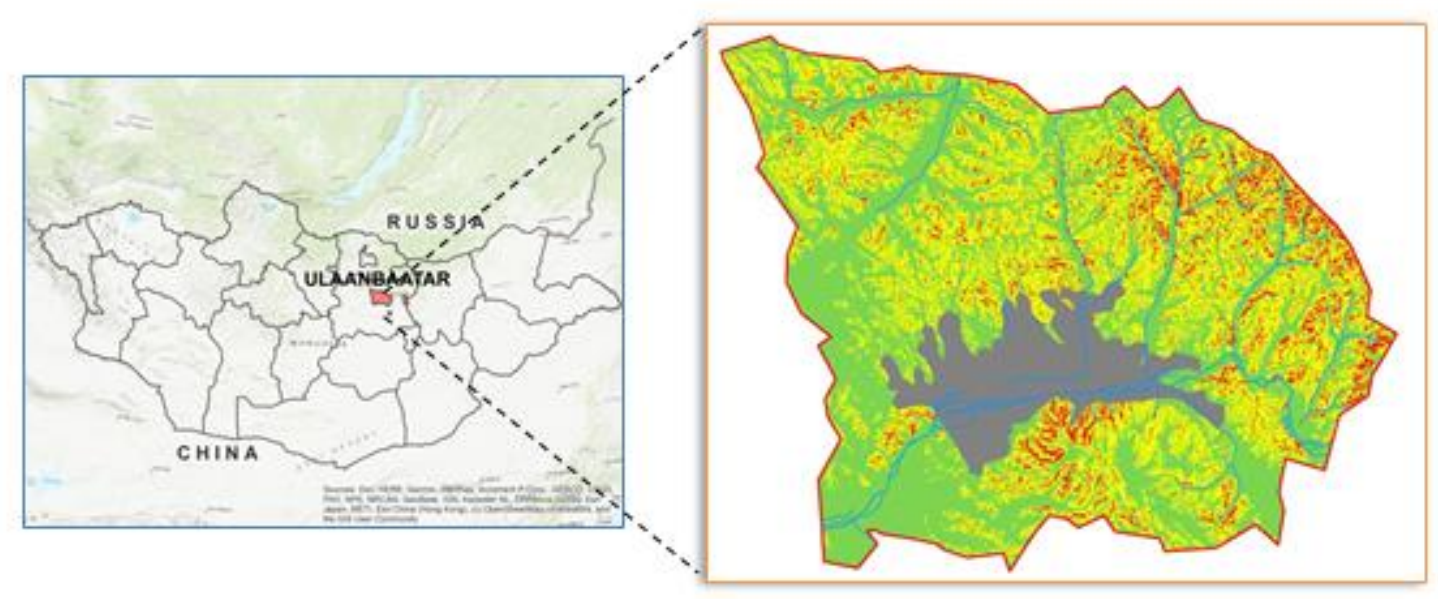

(a)

(b)

Figure 2: Map of the study area. (a) location of Ulaanbaatar city; (b) area suitable for settlement;

\subsection{Data sources and processing}

The current scattered urban sprawl of Ulaanbaatar city needs to be displayed by spatial indicators. Hence, base data for identifying Ulaanbaatar city settlement zone area was prepared using the geographic information system based on the Landsat-1990, Landsat-1995, Landsat-2000, Landsat-2005, Quickbird-2010, World View-2015, Sentinel2-2020 satellite data with the frequency of 5 years covering the period of 1990-2020. Based on the above data, Ulaanbaatar City sprawl area change was identified using the GIS vector overlay tool. Satellite data was uploaded for each year, settlement zone boundaries were mapped by digitizing, then vector and raster data for each year was overlaid using Arc GIS 10.5 software to identify area and perimeter for each year. GIS provides many tools for handling all issues related to land resource management. One of the key characteristics of GIS technology is that it is capable of handling and combining different types of data very precisely [9].

\subsection{Research methods}

In order to determine the reasons for Ulaanbaatar city sprawl, analyses were made of six urban development master plans using monograph and deduction methods. Monocentric, polycentric and compact city concepts were compared with the goal of improving Ulaanbaatar City current land use form, intensifying land use and decreasing the scattered urban sprawl. The impact of each urban development concept on urban sprawl was comparatively analyzed using 6 indicators of land use efficiency [10-12] and land use form [12-14].

\subsubsection{Measuring land use efficiency}

As mentioned above, 3 indicators were selected to identify the land use efficiency. This includes floor area ratio; population density and building coverage. Settlement zone population density determines the building capacity and utilization rate. A low rate of building utilization demonstrates low population density, whereas an increase in building height and site area should result in more dense population. Population density in the 
developed zone serves as a significant factor in decreasing urban sprawl; therefore, it was selected as an indicator. This is expressed in the following formula.

$$
\mathrm{d}=\frac{\mathrm{P}}{\mathrm{A}}
$$

$\mathrm{d}-$ building area population density

$\mathrm{P}$ - population size

A - site area

The bigger the value " $d$ " is, the higher the capacity of the development area [12]. Even though the population density is increased, unless the floor and area ratio is increased, it will still demonstrate that building capacity hasn't improved. In terms of the need to improve the efficiency of land use, the capacity of building should be increased. Therefore, floor and area ratio was selected to be a measurement of land use efficiency.

$$
F A R=\frac{\sum_{i=1}^{\mathrm{t}} \mathrm{A}_{i}}{\mathrm{~S}_{\mathrm{L}}}
$$

$\mathrm{Ai}$ - site area,

$\mathrm{t}$ - total floor area

SL - unit area size

FAR - floor area ratio.

The higher the value of the construction area FAR is, the bigger the capacity of the building. This means that land use is more efficient [10]. A city expands not only outwards but also inwards due to building density. When the building coverage ratio increases due to land use efficiency, it causes sprawl in the urban development area, hence the city's inner form is lost leading to such negative impacts as reduction in public use area, roads and green area. The process of urban inward sprawl caused by increased building area is defined by the building coverage ratio.

$$
B C R=\sum \frac{\mathrm{F}}{\mathrm{A}}
$$

$\mathrm{F}$ - building area;

A - site area;

BCR - building coverage ratio [11].

\subsubsection{Measuring change in land use form}

Dimensions of land use form change can be easily shown on a map, areal and satellite images, hence comparative analyses were made using the following 3 indicators, i: fractal dimension, compactness index, and Feret's diameter. There are several methods to measure fractal dimension including "self-similarity", "divider", "Hausdorff”, "correlation", "box counting dimension", "dilation dimension" and others $[15,16]$. Fractal dimension is calculated as mentioned above using a map and aerial and satellite imagery, hence "box counting dimension" is used on this research. This method was first identified by Mandelbrot [17] and is used in detecting fractions of complex forms such as urban morphology [18]. Fractal dimension values range between 1 and 2 , and if the forms are more complex, the fractal dimension value approaches 2 [19]. The following formula was employed for the calculation of each land-use fractal dimension [20].

$$
D=\frac{2 \log \mathrm{P} / 4}{\log \mathrm{A}}
$$

D- fractal dimension; 
P- external perimeter of urban land-use area;

A- area of urban land use.

Feret diameter is calculated with the following formula using the maximum distance between a pair of coordinates [21] and maximum distances covering each land use [22].

i,d - land use end coordinates.

$$
F=\max _{i, i+1\left(d_{i, i+1}\right)}
$$

Feret diameter presents land use form ratio within $F \leq 1$ value range, when $F=1$ shape perimeter resembles a square, if $\mathrm{F}$ value approaches 0 , shape form ratio is lost and tends to stretch to one side. Shape ratio in urban geographic research is the key indicator for urban sprawl. Therefore, change in shape ratio demonstrates urban sprawl in the following way; if the city expands outwards shape ratio decreases, whereas increased internal density causes increased shape ratio [23]. In 1982 Ritter et al [24] attempted to identify a simple ratio by comparing the shape perimeter to its area when defining the shape density, the basic method for which was developed by Richardson [25].

$$
C=\frac{2 \sqrt{\pi A}}{P}
$$

$\mathrm{C}$ - land use density rate;

$\mathrm{P}$ - total land use perimeter;

A - land use area.

\section{Results}

\subsection{Spatial analysis of urban sprawl of Ulaanbaatar city}

Ulaanbaatar's 1990, 1995, 2000, and 2005 LANDSAT satellites, 2010's Quickbird, 2015's World View, and 2020's Sentinel2-2020 satellites were used to determine the extent of the urban sprawl. In 1990-1995, expansion increased by 540 hectares, in 1995-2000 by 3,871 hectares, in $2000-2005$ by 2,185 hectares, in 2005-2010 by 9,285 hectares, in 2010-2015 by 9,484 hectares, and in $2015-2020$ by 3,210 hectares.
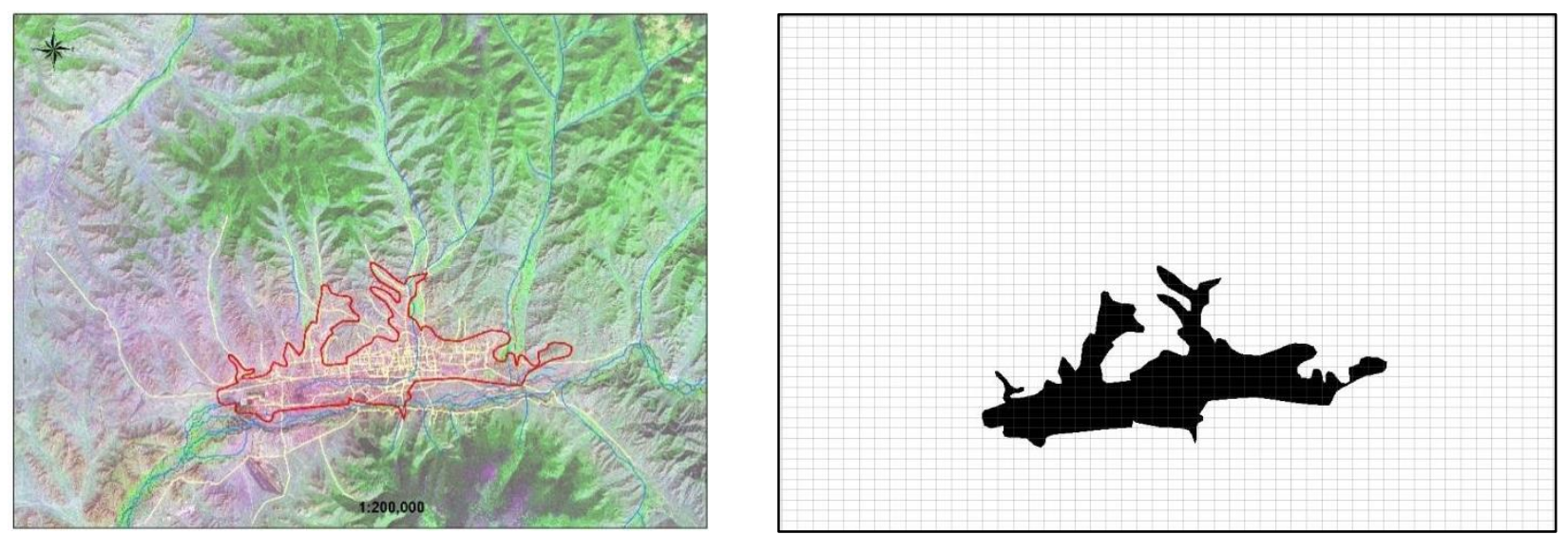

(a) 

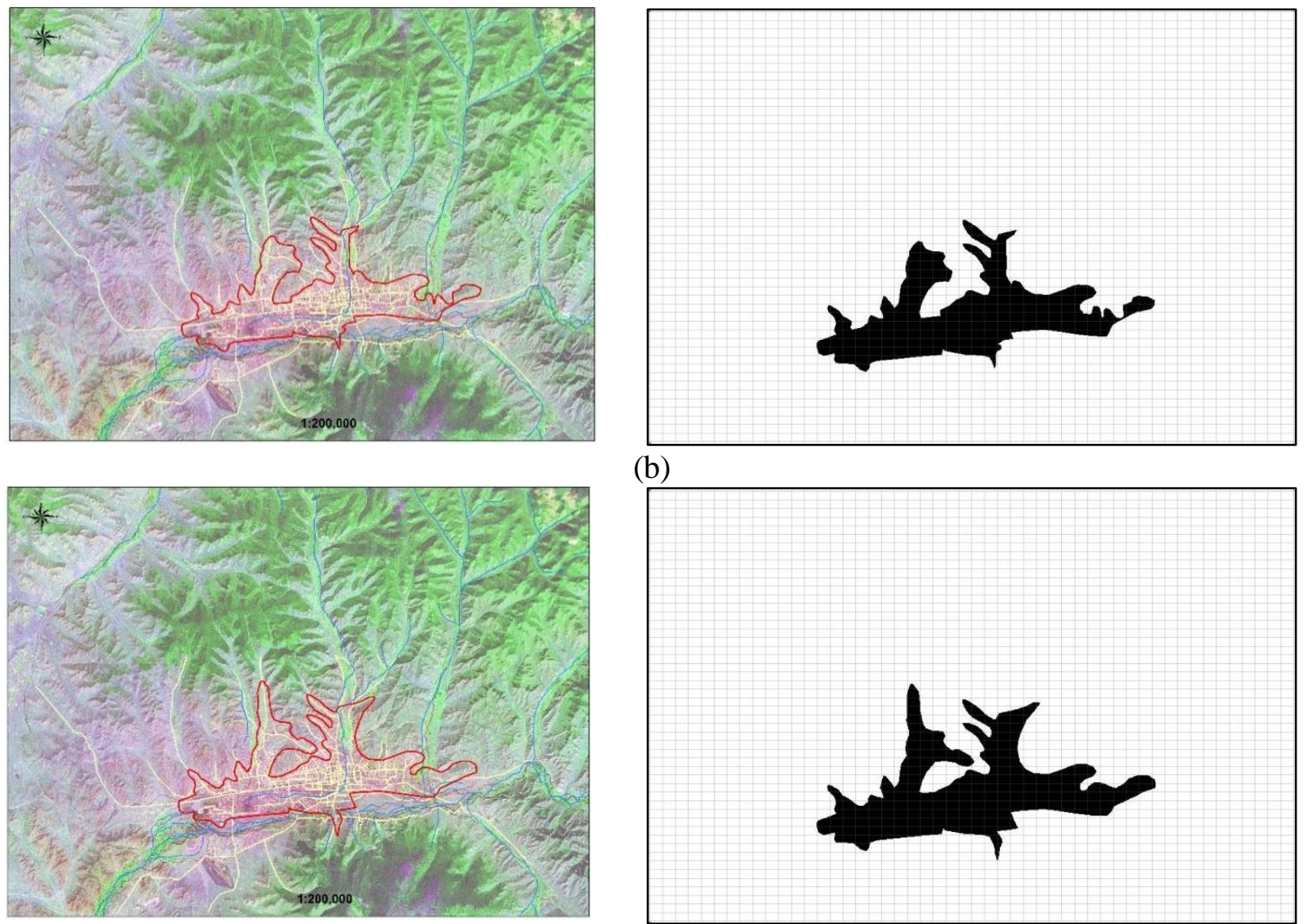

(b)
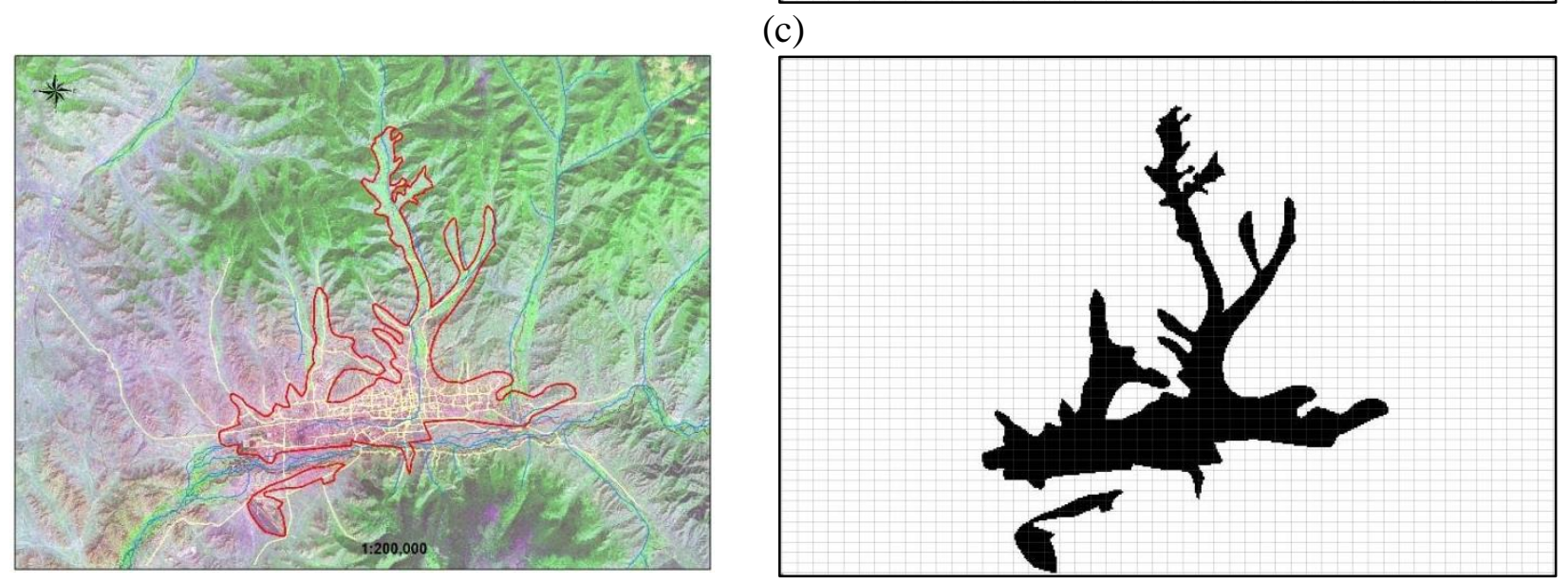

(d)
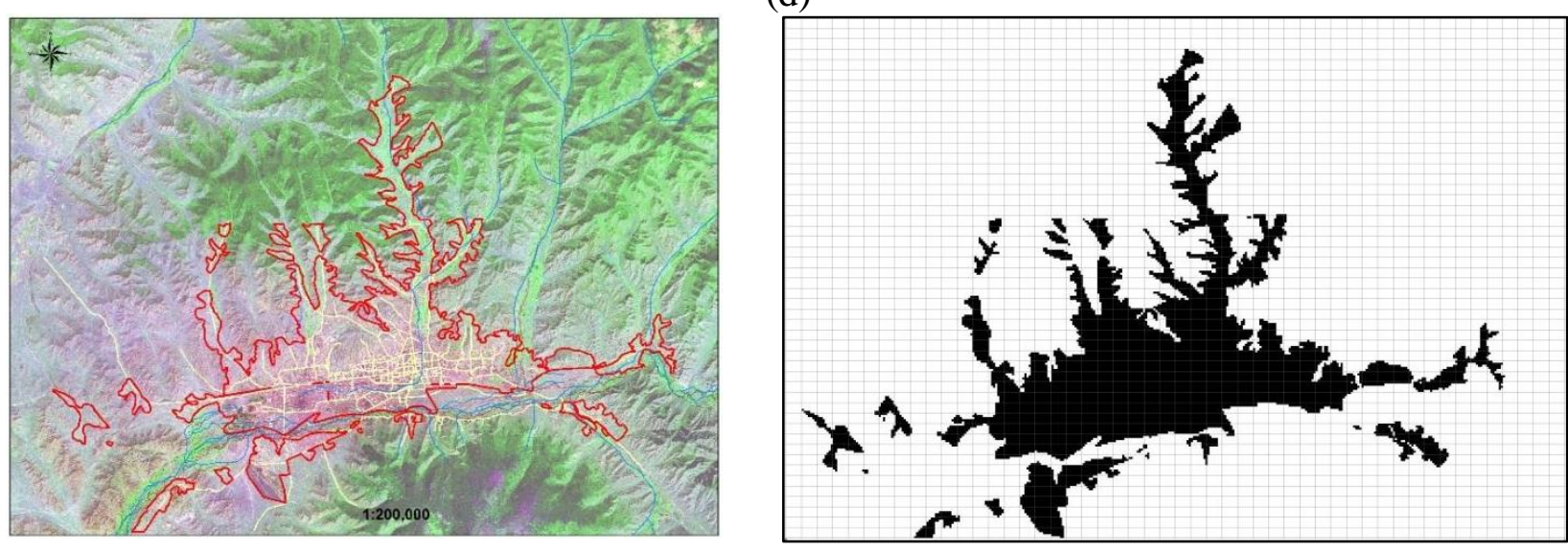

(e)

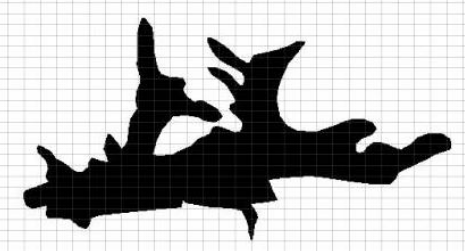

$$
\text { (e) }
$$



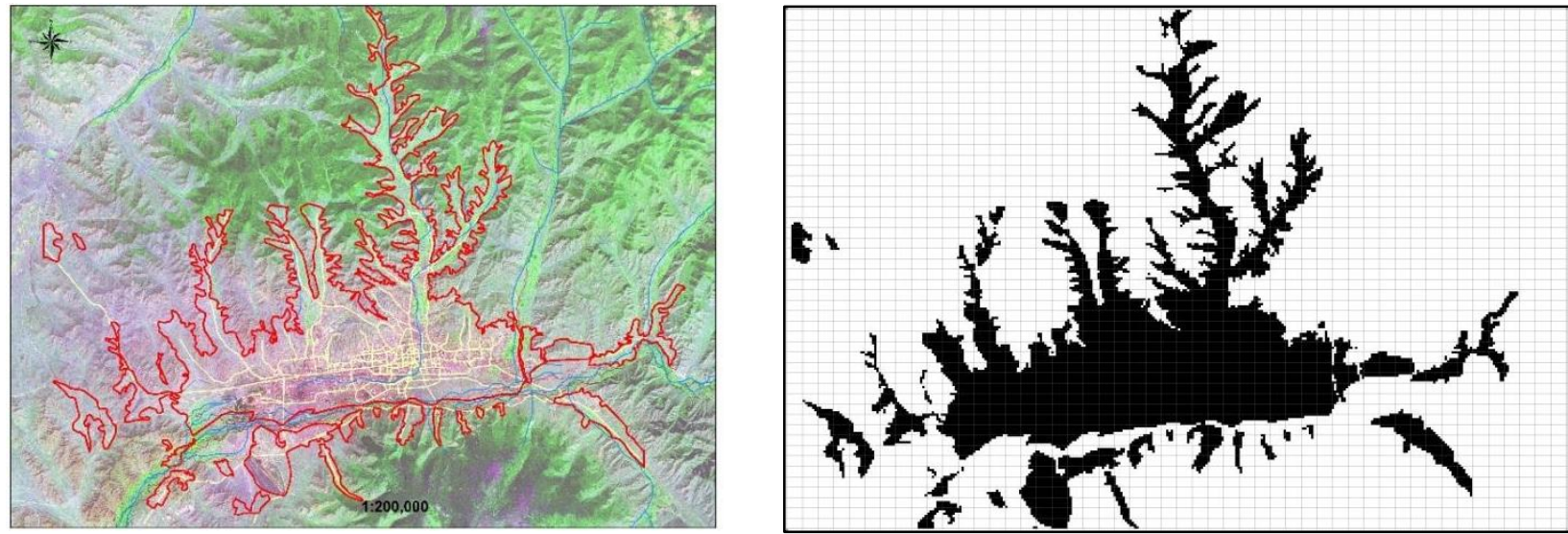

(f)
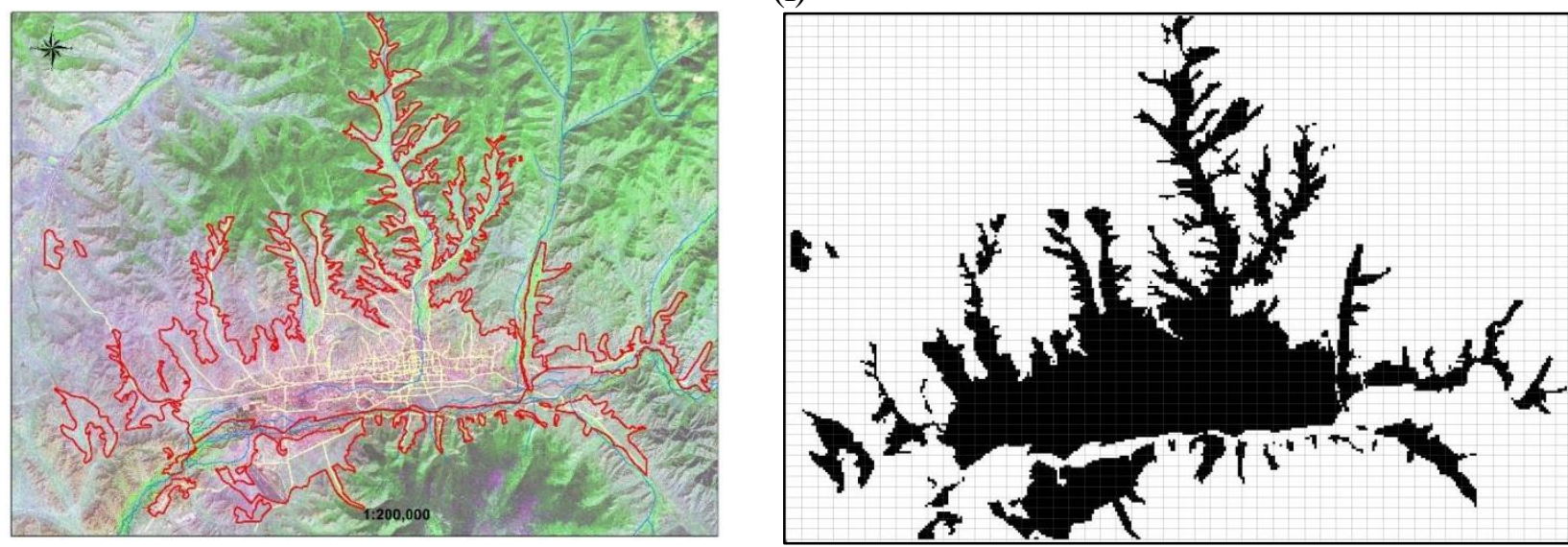

(g)

Figure 4: Map of the urban sprawl. (a) 10,730 hectares by 1990; (b) 11,270 hectares by 1995; (c) 15,141 hectares by 2000; (d) 17,326 hectares by 2005; (e) 26,541 hectares by 2010; (f) 36,025 hectares by 2015; ( $g$ ) 39,235 hectares of 2020;

Based on the above data, the following results were obtained to determine the spatial changes in land use.

Table 2: Changes in land use form of Ulaanbaatar city (1990-2020)

\begin{tabular}{cccccccc}
\hline Он & $\begin{array}{c}\text { Area } \\
\text { ha/ }\end{array}$ & Perimeter & $\begin{array}{c}\text { Feret's } \\
\text { diameter } \\
/ \mathrm{max} /\end{array}$ & $\begin{array}{c}\text { Feret's } \\
\text { diameter } \\
/ \mathrm{min} /\end{array}$ & $\mathrm{F}$ & $\mathrm{C}$ & $\mathrm{D}$ \\
\hline 1990 & 10370 & 112600 & 27321 & 12183 & 0.44 & 0.32 & 1.11 \\
1995 & 11270 & 115300 & 27606 & 12184 & 0.44 & 0.33 & 1.11 \\
2000 & 15141 & 155927 & 25955 & 12155 & 0.47 & 0.28 & 1.12 \\
2005 & 17326 & 220076 & 27270 & 26390 & 0.97 & 0.21 & 1.15 \\
2010 & 26541 & 483850 & 45880 & 27580 & 0.60 & 0.12 & 1.21 \\
2015 & 36025 & 697519 & 48370 & 33140 & 0.69 & 0.1 & 1.23 \\
2020 & 39235 & 772190 & 50321 & 36932 & 0.73 & 0.09 & 1.23 \\
\hline
\end{tabular}




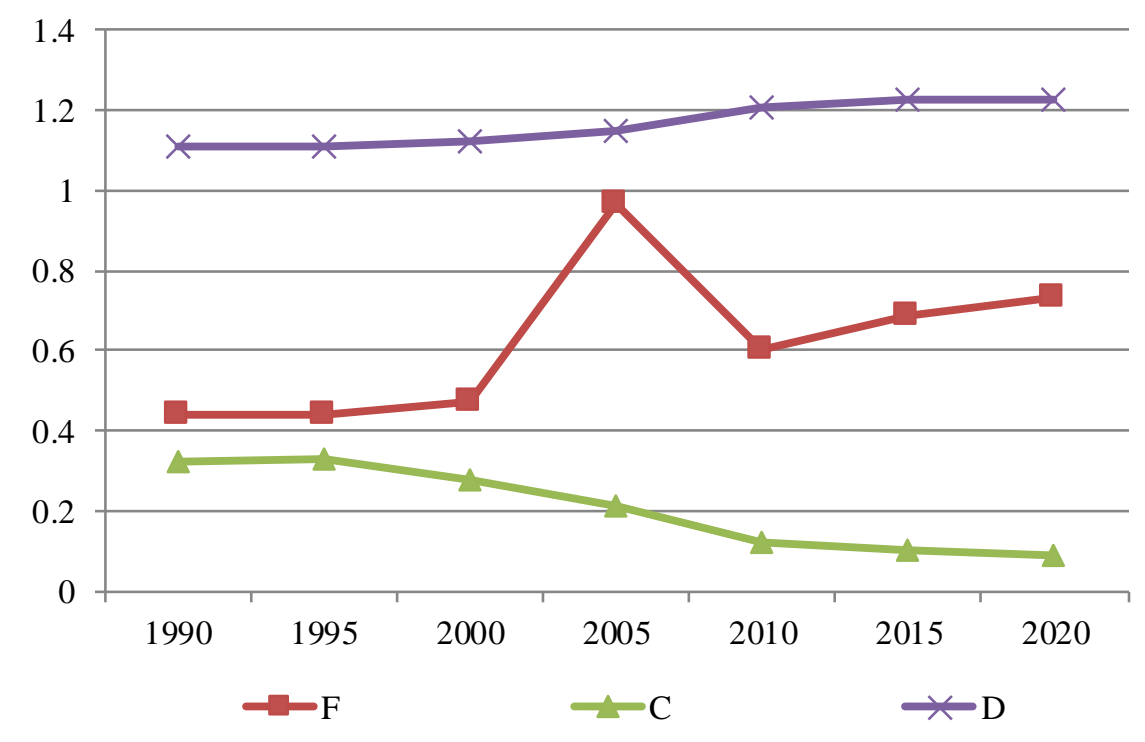

Figure 5: Changes in land use form of Ulaanbaatar city (1990-2020)

According to Table 2, Feret's ratio was 0.44 in 1990, indicating that Ulaanbaatar had a horizontal structure, and 0.73 in 2020, indicating that the expansion of land use form has expanded mostly vertically over the last 20 years. However, considering this ratio every 5 years, in 1990-1995 and 1995-2000, the ratio expanded horizontally between 0.44 and 0.47, and between 2000 and 2005 the ratio increased to 0.97 , thus, the urban form expanded vertically and the structure of the city became relatively proper. In 2005-2010, the ratio expanded to 0.60 in the horizontal direction, while in 2010-2015 it increased to 0.69 , and in 2015-2020 it expanded to 0.73 back in the vertical direction. The compactness ratio of Ulaanbaatar has been steadily declining from 0.28 to 0.09 over the past 15 years, indicating that Ulaanbaatar has expanded rapidly with low urban density. The fractal dimension rate is 1.23, which is the second level of the four-level [26] classification from the School of Geography at the University of Florida in the United States. This indicates that the city is expanding in a chaotic and clustered manner.

\subsection{Comparison between urban planning concepts}

\subsubsection{Analysis of mono-centric concept of Ulaanbaatar city}

The first master plan for Ulaanbaatar, that has become the foundation of development, was approved in 1954, and its population was expected to reach 125,000 in the next 20 years. The second master plan was developed and approved in 1961, and is scheduled for another 20 years, with a population of 250,000. The plan was implemented over a relatively slow period of 14 years compared to the original plan, during which time Ulaanbaatar expanded along the Tuul River valley to a length of $20 \mathrm{~km}$ and a width of $6-8 \mathrm{~km}$, with a built-in area of 3,900 ha. As the city's population reached 348.7 thousand in 1975, a third master plan was developed and 19 apartment districts were planned, increasing the housing stock by $79 \%$ compared to 1960 [4]. During the implementation of this plan, Ulaanbaatar has regained its current appearance, but the main drawback was the miscalculation of population growth, as in the previous plan. During the implementation of the third master plan, the population was 
expected to increase by 50-80 thousand, but in reality, the capital city's population doubled to 492.2 thousand, hence, it was necessary to update the master plan ahead of time.

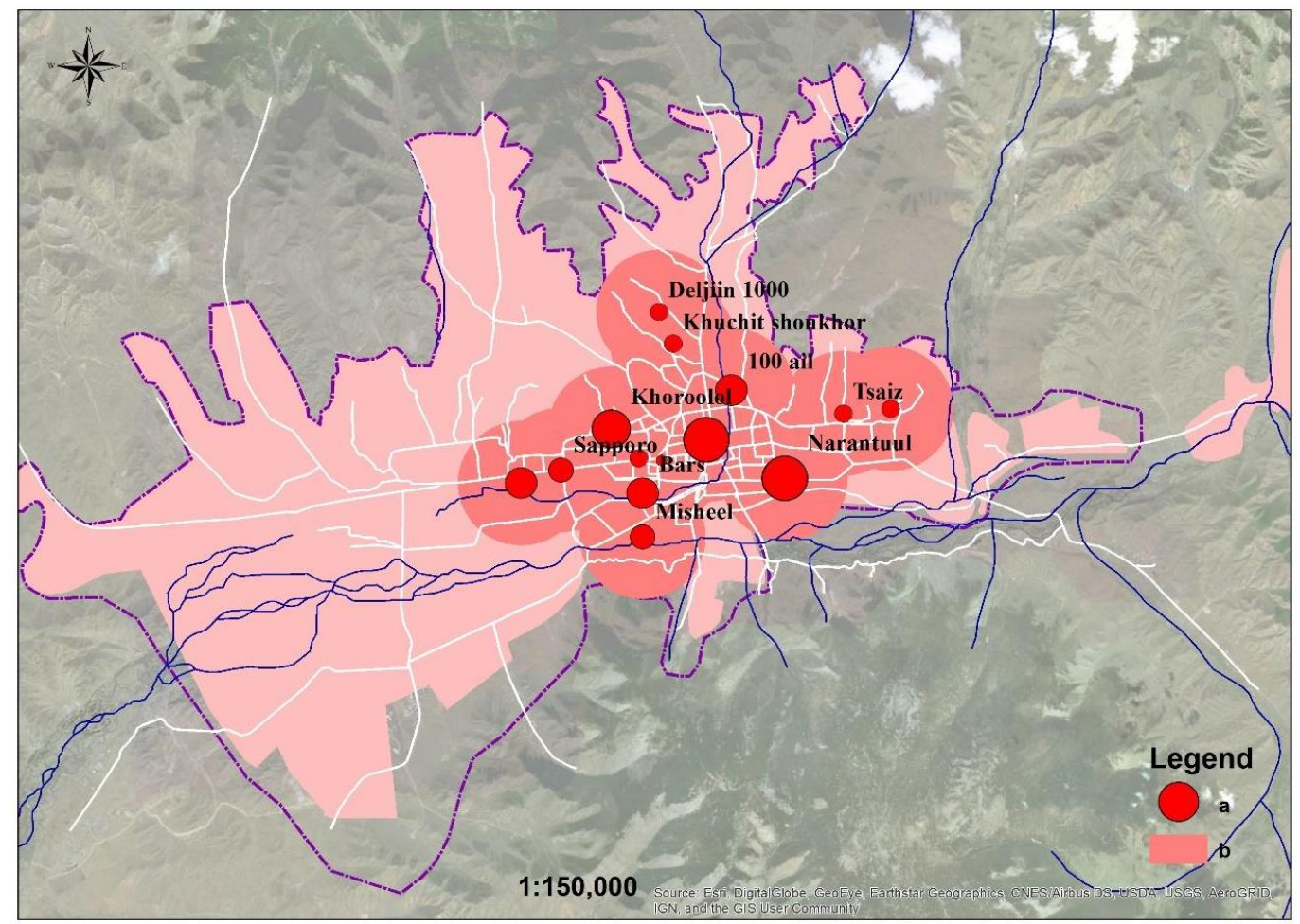

Figure 6: Map over the monocentric.(a) population concentration points; ( $b$ area suitable for settlement;

Land use efficiency analysis. The following results were obtained from a random sampling of 19 districts in the residential area that were created within the framework of the master plan, and an analysis of land use efficiency was conducted.

Table 3: Land efficiency of Monocentric

\begin{tabular}{llcc}
\hline № & Indicator & Unit of measurement & Before the project \\
\hline 1 & Building coverage ratio & $\%$ & 33.7 \\
2 & Population density & People per ha & 65.6 \\
2 & Floor area ratio & unit & 1.6 \\
\hline
\end{tabular}

The table shows that the BCR in the residential area formed during the monocentric concept is $33.7 \%$, which is a low density residential area, the FAR is 1.6 , which means there were a lot of low-rise buildings, and the population density is 65.6 people per ha, which indicates a small number of residents. In other words, low-rise residential buildings of 1-5 floors were built within big distances in this area. The results of the study suggest that the monocentric concept favors low-density urbanization over a relatively large area. Therefore, 65.6 people per ha, which is a relatively small number of people, live in the 17,326 ha area, or more than half of Ulaanbaatar's suitability zone. 
Land use form analysis: According to the analysis of the monocentric concept, the general plan solution developed during the concept was changed in 1986, but due to the social transition period until 2010, the quantitative value of 2010 was used to measure the expansion.

Table 4: Fractal dimension of Monocentric (MC)

\begin{tabular}{cccccccc}
\hline Term & $\begin{array}{c}\text { Area } \\
\text { /ha/ }\end{array}$ & Perimeter & $\begin{array}{c}\text { Feret's } \\
\text { diameter } \\
/ \mathrm{max} /\end{array}$ & $\begin{array}{c}\text { Feret's } \\
\text { diameter } \\
/ \mathrm{min} /\end{array}$ & $\mathrm{F}$ & $\mathrm{C}$ & $\mathrm{D}$ \\
\hline $\mathrm{MC}$ & 26541 & 483850 & 45880 & 27580 & 0.60 & 0.12 & 1.21 \\
\hline
\end{tabular}

Since Ulaanbaatar is located along a river valley, the expansion is spread horizontally depending on the main road network and the distance to the center, as shown by Feret's aspect ratio (0.60) from Table 4. A low compactness index of 0.12 indicates an outward expansion, and a fractal dimension of 1.21 indicates a clustered form. In general, the expansion formed by this monocentric concept resulted in a transverse, chaotic, and lowdensity settlement.

\subsubsection{Analysis of polycentric concept of Ulaanbaatar city}

The city's population reached 492.2 thousand in 1986, and the fourth master plan was developed as the indicators of the third master plan changed. Approved in 1986, the plan proposed a polycentric approach to decentralization and relocation to suburban areas through a system of group settlements, but failed in 1990 due to a change of government and an economic crisis and has been forgotten for over 10 years. During this period, land use form in the capital city continued to be largely unregulated and chaotic, requiring more evaluation of its future planning and management, and the identification of land use trends [3]. In line with this requirement, the 5th master plan, the plan for the development of the capital city of Ulaanbaatar until 2020, was developed and approved in 2002. Although this plan is unique in that it was the first of its kind in which Mongolians developed the plan by themselves, it was essentially a continuation of the polycentric concept of the Fourth Master Plan, developed in 1986. The main content of the master plan is to create an optimal territorial system for development of the capital's satellite settlements in order to decentralize the urban population. Therefore, during the planning period, Ulaanbaatar was considered to be a self-sustaining and competitive territorial and economic complex with 15 satellite towns and villages, and 4 zones. Although 10 years have passed since the implementation of the Master Plan, the development of peri-urban towns and villages has remained stagnant, centralized and dependent on Ulaanbaatar, which has made it impossible to control the flow of migrants, resulting in urban sprawl of Ulaanbaatar city. Adverse effects such as air pollution, traffic congestion, and soil pollution have increased. This situation indicates that the implementation of the plan is insufficient and needs to be clarified [4]. Thus, in 2012, the 6th master plan for the development of Ulaanbaatar until 2025 was developed, which estimates that the population of Ulaanbaatar will be 1.4 million. In order to avoid the current centralized system of the city, it became clear that the development of satellite villages could not be implemented, so it is planned to develop the city's internal architectural space into 8 subcenters in order to partially solve problems facing the city. 


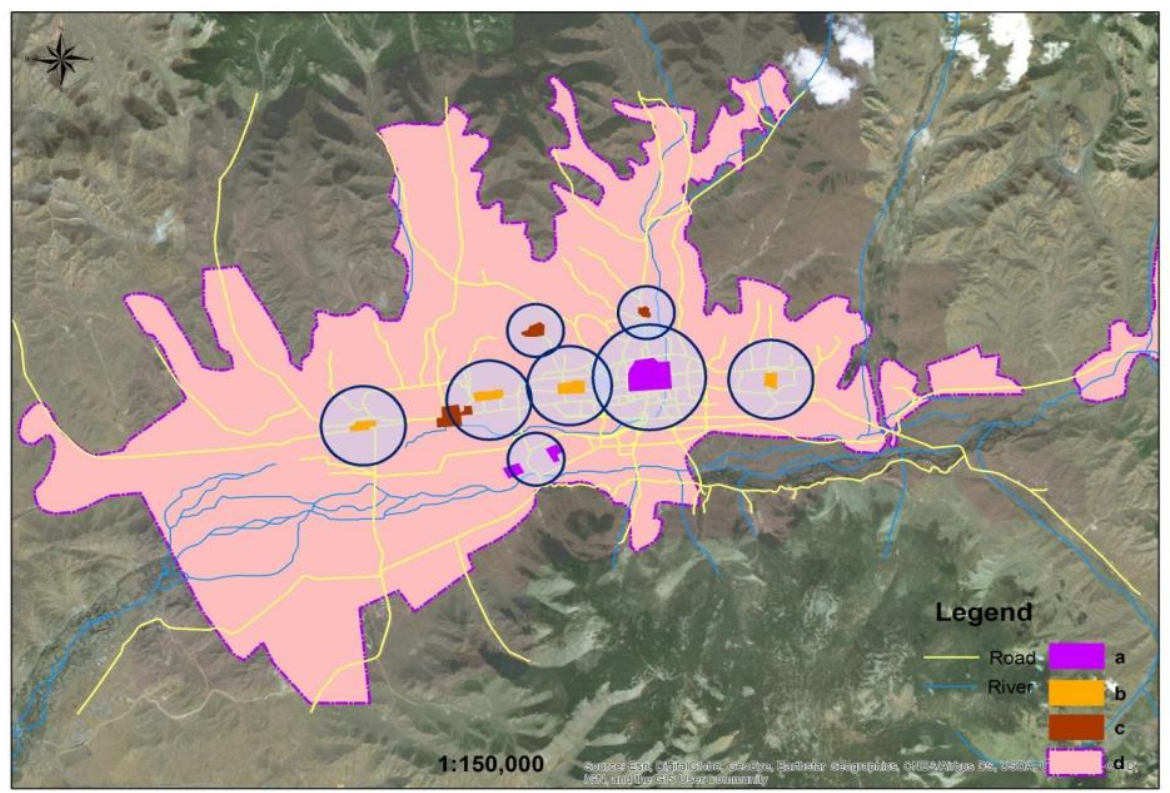

Figure 7: Planned polycentric. (a)city center; (b)district center; (c)planned sub-centers, (d) area suitable for settlement

Each sub-center will have its own complex of administrative, trade, services, cultural, educational, sports, and social infrastructure service centers, and will be responsible for providing social infrastructure to the unrestricted settlement areas created by urban sprawl.

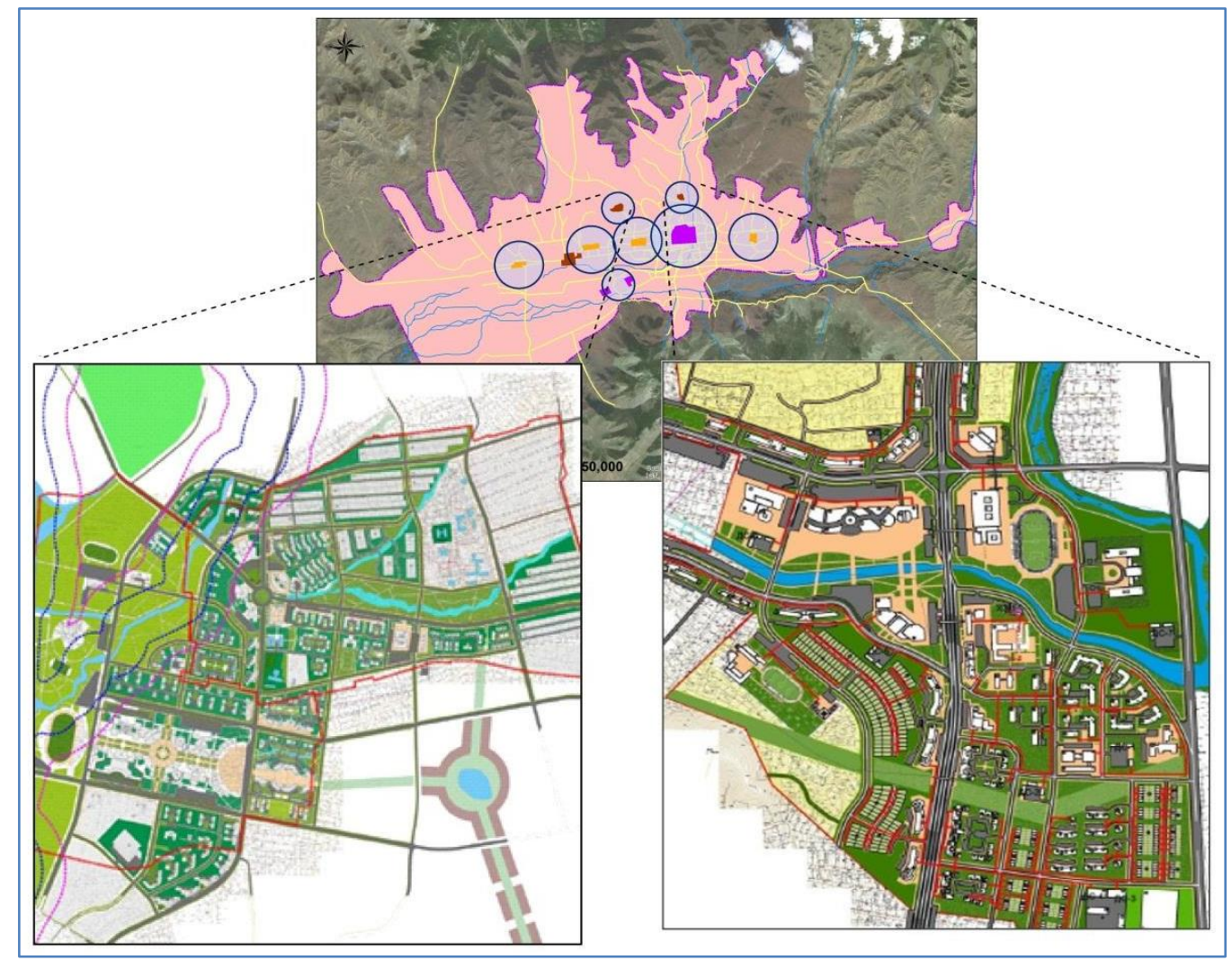

(a)

(b)

Figure 8: Planned sub-centers. (a) Bayankhoshuu sub-center; (b) Selbe sub-center 
Currently, 4 years have passed since the establishment of Selbe and Bayankhoshuu subcenters in accordance with the plan, and other social infrastructure works are presently underway.

Land use efficiency analysis: As mentioned above, the master plan will be implemented over 9 years, so we analyzed the expected results of the plan.

Table 5: Land efficiency of Polycentric

\begin{tabular}{clcc}
\hline № & \multicolumn{1}{c}{ Indicator } & Unit of measurement & Before the project \\
\hline 1 & Building coverage ratio & $\%$ & 43.7 \\
2 & Population density & People per ha & 50 \\
2 & Floor area ratio & unit & 1.8 \\
\hline
\end{tabular}

The table shows that the BCR in the residential area planned in the polycentric concept is $43.7 \%$, which is a low density residential area, the FAR is 1.8 , which indicates that there are a lot of low-rise buildings, and the population density is 50 people per ha, which points to a small number of residents. Although BCR and FAR have increased, the population density is lower than in the monocentric concept city. This is due to the fact that the two sub-centers are responsible for providing social infrastructure for the entire unrestricted settlement area in the northern region.

Land use form analysis. In terms of the polycentric concept, the quantitative values from 2020 are used to measure the urban expansion scale, as they are the main outcome of the current master plan.

Table 6: Fractal dimension of Polycentric (PC)

\begin{tabular}{cccccccc}
\hline Term & $\begin{array}{c}\text { Area } \\
\text { /ha/ }\end{array}$ & Perimeter & $\begin{array}{c}\text { Feret's } \\
\text { diameter } \\
/ \mathrm{max} /\end{array}$ & $\begin{array}{c}\text { Feret's } \\
\text { diameter } \\
/ \text { /min/ }\end{array}$ & F & C & D \\
\hline PC & 39235 & 772190 & 50321 & 36932 & 0.73 & 0.09 & 1.23 \\
\hline
\end{tabular}

In a polycentric development concept the sub-centers are planned to expand vertically in terms of urban land use form, with a Feret's aspect ratio of 0.73 and a compactness ratio of 0.09 in order to provide the social infrastructure to reduce the urban sprawl. Due to this process, the fractal dimension, which is an indicator of the urban growth dynamics, has reached 1.23 , indicating that the form of the city has become clustered and chaotic.

\subsubsection{Analysis of compact city concept of Ulaanbaatar city}

A compact city is one of the most well recognized sustainable urban forms [27]. In modern times, the concept of a compact city is understood as a planning approach that limits urban sprawl in the face of rapid population growth and leads to a more densely populated urban land use form [28]. Although the form of a city may vary depending on the characteristics and planning objectives of the city, Danztig and Saati [29] first defined the concept as having 
high urban density, less dependence on the car, and common features of everyday life [30]. In this sense, the key solution to the concept is to reduce urban sprawl by creating a high density residential area with tall buildings in the readjustment zone of Ulaanbaatar. Land readjustment is a key tool for implementing the compact city concept [31-33]. It not only helps to improve the urban land use form, but also helps landowners to increase the economic efficiency of their land [34]. In addition, the land readjustments affect many fields, such as housing land supply, urban-sprawl prevention, reconstruction after disasters, and readjustment in commercial areas [35]. In the central part of Ulaanbaatar, there are 1,413 buildings built during the monocentric concept in the area of 4,604.87 hectares. Resolutions 01-01/05 in 2014, 01-01/08 in 2016, 02-01/03 and, 02-01/04 in 2017 of the Ulaanbaatar City Specialized Inspection Agency banned the use of 808 apartment buildings in this area that did not meet operational requirements and were not earthquake-resistant, and decided to demolish these buildings and implement land readjustment. Urban expansion can be reduced by implementing the compact city concept in this area. The spatial parameters in the current residential area of 9-16 story apartments in Ulaanbaatar were measured on average in order to determine the quantitative value of the urban expansion.

Land use efficiency analysis: Average data from 10 densely populated 9-16 story apartment districts in Ulaanbaatar were used to calculate the indicators of land use efficiency.

Table 7: Land use efficiency of Compact city

\begin{tabular}{llcc}
\hline № & Indicator & Unit of measurement & Before the project \\
\hline 1 & Building coverage ratio & $\%$ & 57.8 \\
2 & Population density & People per ha & 316 \\
2 & Floor area ratio & unit & 4.9 \\
\hline
\end{tabular}

Urban land readjustment projects and programs will be key tools for implementing the compact city concept. Therefore, the implementation of the compact city concept in the area of 4,604.87 hectares for land readjustment and the calculation of the population density data of 316 people / ha yielded the following results regarding the urban carrying capacity of the region.

Table 8: Estimation of increase in urban carrying capacity

\begin{tabular}{llccccc}
\hline № & $\begin{array}{c}\text { Average } \\
\text { population } \\
\text { density /before/ } \\
\text { people/ ha }\end{array}$ & $\begin{array}{c}\text { Average } \\
\text { population } \\
\text { density } \\
\text { /after/ } \\
\text { people/ ha }\end{array}$ & $\begin{array}{c}\text { Area size } \\
\text { /ha/ }\end{array}$ & $\begin{array}{c}\text { Population } \\
\text { /now/ }\end{array}$ & $\begin{array}{c}\text { Population } \\
\text { /after the } \\
\text { project/ }\end{array}$ & Difference \\
\hline $\begin{array}{l}\text { Land } \\
\text { readjust } \\
\text { ment } \\
\text { area }\end{array}$ & 65.6 & 316 & $4,604.87$ & 302079 & 1455139 & 1153060 \\
\hline
\end{tabular}


With the implementation of the compact city concept, a total number of 1,153,060 people will be able to settle in the land readjustment area. Estimating this data in accordance with the general land management plan of Ulaanbaatar, the urban expansion can be reduced by 26,756 hectares and the total area will become 12,479 hectares.

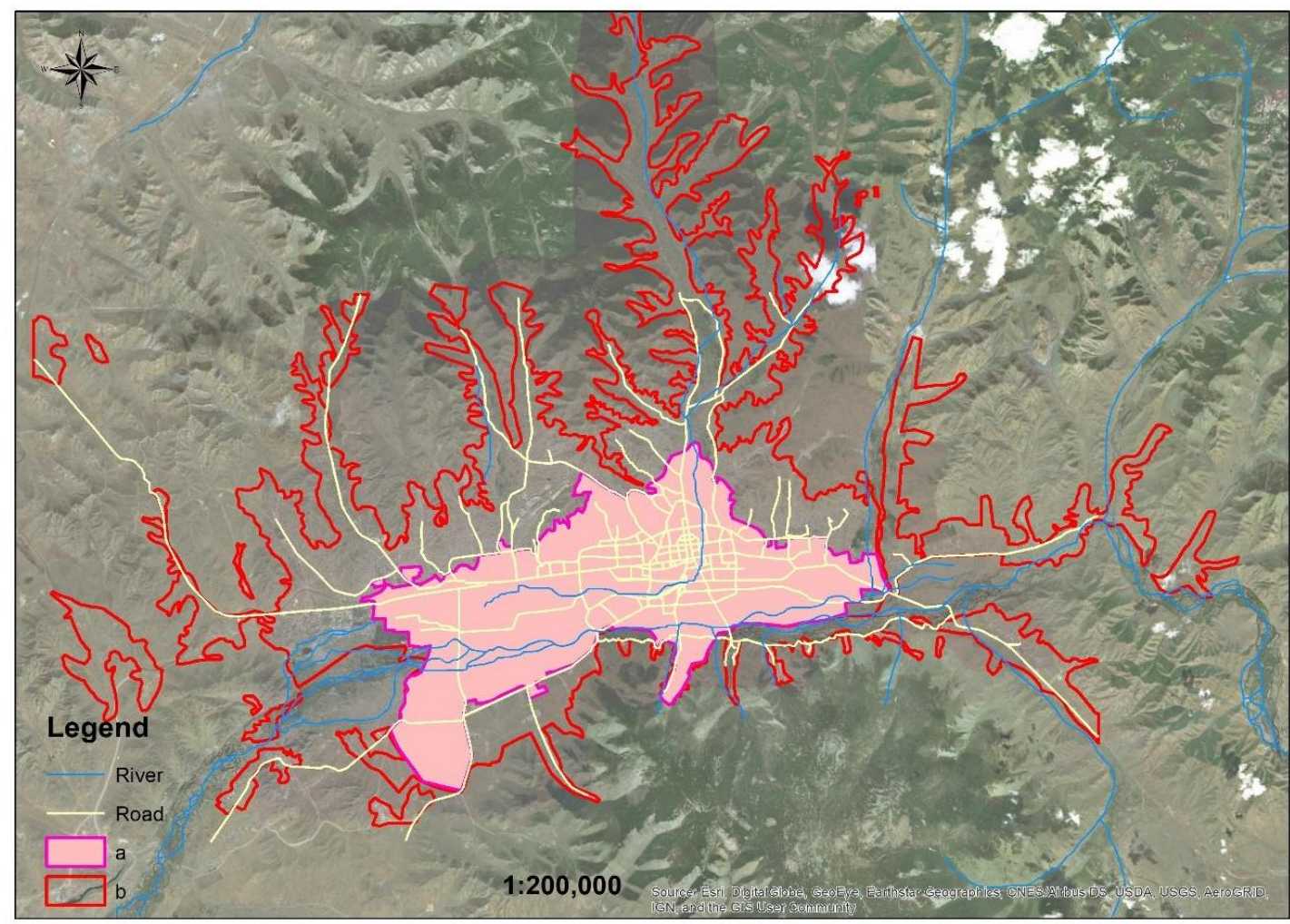

Figure 9: Map over the compact city: (a) after implemented compact city; (b)urban sprawl by 2020

Land use form analysis. The concept of compact city is based on the results of the analysis of densely populated, high-rise residential areas, which are used as the above quantitative values.

Table 9: Land use form analysis of Compact city (CC)

\begin{tabular}{cccccccc}
\hline Term & $\begin{array}{c}\text { Area } \\
\text { /ha/ }\end{array}$ & $\begin{array}{c}\text { Perimete } \\
\mathrm{r}\end{array}$ & $\begin{array}{c}\text { Feret's } \\
\text { diameter } \\
/ \mathrm{max} /\end{array}$ & $\begin{array}{c}\text { Feret's } \\
\text { diameter } \\
/ \mathrm{min} /\end{array}$ & $\mathrm{F}$ & $\mathrm{C}$ & $\mathrm{D}$ \\
\hline $\mathrm{CC}$ & 12479 & 97837 & 22300 & 13600 & 0.61 & 0.40 & 1.08 \\
\hline
\end{tabular}

In terms of the compact city concept, as mentioned above, the density of the city center was quadrupled to 0.40 and the area to be built was reduced to $12,479.7$ ha. However, the fact that the fractal dimension, which is an indicator of the urban growth dynamics, is 1.08 shows that the pattern of urban sprawl has improved.

\subsection{Comparison between urban planning concepts}

To compare the impact of the sprawl in urban planning concepts, it is necessary to combine the corresponding quantitative values of urban land use form and land use efficiency during 
their implementation. The quantitative values related to the urban sprawl of the settlement area are as follows.

Table 10: Comparison of urban concepts (mc-monocentric, pc-polycentric, cc-compact city)

\begin{tabular}{|c|c|c|c|c|c|c|c|c|c|c|}
\hline $\begin{array}{l}\text { Ter } \\
\mathrm{m}\end{array}$ & $\begin{array}{l}\text { Area } \\
\text { /ha/ }\end{array}$ & 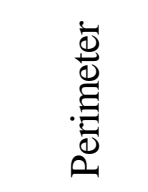 & 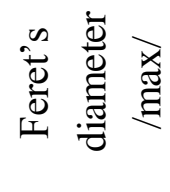 & 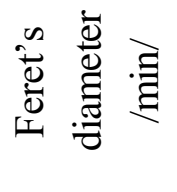 & $\mathrm{F}$ & $\mathrm{C}$ & D & BCR & FAR & $\mathrm{P}(\mathrm{r})$ \\
\hline $\mathrm{MC}$ & 26541 & 483850 & 45880 & 27580 & 0.60 & 0.12 & 1.21 & 33.7 & 1.6 & 65.6 \\
\hline $\mathrm{PC}$ & 39235 & 772190 & 50321 & 36932 & 0.73 & 0.09 & 1.23 & 43.7 & 1.8 & 50 \\
\hline $\mathrm{CC}$ & 12479 & 97837 & 22300 & 13600 & 0.61 & 0.40 & 1.08 & 57.8 & 4.7 & 316 \\
\hline
\end{tabular}

The table shows that the built-up area of the compact city concept is less than the current polycentric concept area by 26,756 ha, and 14,062 ha less than the built-up area of the monocentric concept. Thus, the compact city concept may be effective in reducing the urban sprawl of Ulaanbaatar.

Land use form analysis. According to Table 10, Feret's aspect ratio is 0.60 in the monocentric concept and 0.61 in the compact city concept, of which both elongated the land use form in the transverse direction. However, in the polycentric concept Feret's aspect ratio is 0.69 , which tends to correct the land use form in the vertical direction. In terms of urban compactness, the population density was 0.12 , i.e. sparse, during the monocentric concept, but further decreased to 0.09 during the polycentric concept. In the compact city concept, the population density increases to 0.4. Comparing the results of the fractal dimension, in the monocentric and polycentric concepts dimensions are 1.21 and 1.23, respectively, resulting in a clustered pattern, while in the compact city concept fractal dimension is 1.08 , resulting in the improved shape of the city with reduced curves.

Land use efficiency analysis. According to Table 10, the population density, which was 65.6 people per ha in the monocentric concept, decreased to 50 people per ha in the polycentric concept and increased to 316 people per ha in the compact city concept. The FAR was 1.6 in the monocentric concept, slightly increased to 1.8 in the polycentric concept, and in the compact city concept the ratio has increased by 2.6-2.9 times from the previous 2 concepts, respectively, up to 4.7 . The $\mathrm{BCR}, 33.7$ in the monocentric concept, slightly increased to 43.7 in the polycentric concept, and in the compact city concept the ratio has increased by 1.3 and 1.7 times from the previous 2 concepts, respectively, up to 57.8 .

\section{Discussion}

A significant part of Ulaanbaatar city spatial planning is done ignoring GIS technology based on urban land use form and land use efficiency indicators. Therefore, it is impossible to measure and compare the impact of urban development plans and analyze urban forms. The current Ulaanbaatar city form clearly demonstrates that it is still not easy to choose optimum concepts and solutions in future planning unless proper spatial analyses are done to identify problematic issues. As of today, Ulaanbaatar city urban planning has been applying a combination of monocentric, polycentric and compact city concepts, but in the future a single optimum concept should be identified and implemented. 
The research results suggest that the compact city concept can be applied in the current circumstances of Ulaanbaatar as it reduces urban sprawl threefold, and makes the used area of the city more compact. The justification for becoming more compact is that residential districts with 9-16 floor buildings were used as the basic data. However, not all spatial indicators for the compact city concept turned out to be effective. For instance, two indicators were not that positive which included a Feret ratio that identifies urban land use form and internal spatial sprawl as well as a building coverage ratio. The Feret ratio of 0.61 shows that it is not compatible with the urban land use form ratio. This indicator improves when the polycentric concept is applied and reaches 0.73 , which leads to improvement of land use form ratio. In the case of the compact city concept, the building coverage ratio that shows inward urban sprawl amounts to 57.8, which demonstrates that living conditions and the environment of residents have deteriorated due to a reduction in city center green area and public use areas. If restrictions are imposed on urban form ratio and building coverage ratio, a threefold reduction in urban sprawl would not be possible. This suggests that applying only the compact city concept would be inadequate.

Moreover, in order to identify the compactness of three concepts, some residential and unrestricted settlement area data was collected partially to calculate floor area ratio and building coverage ratio. Such ratio calculation research, covering the entire territory of Ulaanbaatar City, has not been previously carried out. Therefore, there is a need to identify this ratio covering Ulaanbaatar City in its entirety and to create a digital elevation model in the future.

\section{Conclusions}

During 1990-2020, Ulaanbaatar city's residential zone area expanded by 28,505 hectares or 3.6 times and the perimeter by 659,590 meters or approximately 6.8 times. This shows that the estimated area with favorable living conditions was exceeded by 5,537 hectares. According to satellite data of 2020, Ulaanbaatar city has appreciably expanded vertically and concentrated in different parts, which has caused the urban form to eventually break down.

When the monocentric concept was applied, the urban sprawl was less compact with partial concentration and stretched out horizontally. A less compact city concept is supported with a relatively large area of 26,541 hectares, hence around $70 \%$ of the area identified as favorable for suitable settlement is occupied by a somewhat sparse population. Therefore, there are limited possibilities for settling new residents from the countryside into a suitable settlement zone, which has further served as a cause of unorganized urban sprawl.

The polycentric concept allows division of the already formed unrestricted settlement area into sub zones and provides these zones with engineering and social infra structures, hence reducing the pressure imposed on the city center and improving the urban form ratio. However, the urban sprawl continues to be even more intensive and scattered. It is possible that the urban sprawl was accelerated by enabling unrestricted settlement of engineering infrastructures and social welfare.

In the scope of the compact city concept, it is possible to reduce the current urban sprawl threefold by increasing the density of Ulaanbaatar City's central area amounting to 4,604.87 hectares. Although the city's current form is being redressed by condensing urban sprawl, this solution does not provide an optimum ratio for urban land use form. However, the research 
results suggest that it is possible to reduce urban sprawl if the urban land use form ratio and building coverage ratio are planned and implemented at the proper rate. This will further allow the population, which has migrated to the capital city in search of better economic opportunities, to settle in the zone with suitable living conditions. 


\section{References}

1. Paramita, B. The land-use of Bandung, its density, overcrowded area and public facility toward a compact city. Materials Science and Engineering. 2016, 128, 012034.

2. Gantulga, G. Urban land use classification and functional zoning of Ulaanbaatar city, Mongolia; Ph.D dissertation: 2010, 40-56.

3. Narantsatsralt, J. Fundamental problems of land use management in the new socialeconomical condition, a case of Ulaanbaatar; Ph.D dissertation: Ulaanbaatar, Mongolia, 1998, 34-68.

4. Tsahiur, S.; et al. Urban master plan of Ulaanbaatar city; report: Ulaanbaatar, Mongolia, 2013,15-28.

5. Gilbert, A.; Gugler, J. Cities, Poverty and Development: Urbanization in the Third World; Oxford University Press: 1992.

6. Munkhnaran,S.; Enkhtuya,N.; Usukhbayar,G.; Chinbat,B.; Gantulga,G.; Bolormaa,B.; Zaya,Ch.; Ganpurev,D.; Dorligjav,D. Predicting urban extend by SLEUTH urban growth model. Geographic Issues. 2018 (1), 18, 18-38.

7. Myagmartseren, P.; Bazarkhand, T.; Myagmarjav, I.; Munkhnaran, S. The Fractal Geometry of Urban Land Use: The Case of Ulaanbaatar City, Mongolia. Land, MDPI, Open Access Journal. 2018, vol. 7(2), 1-14.

8. Myagmartseren, P.; Chinbat, B.; Gantulga, G. Master Land Use Plan of Ulaanbaatar City; Governor Office of Capital City: Ulaanbaatar, Mongolia, 2012.

9. Myagmartseren, P.; Buyandelger, M.; Brandt, S.A. Implications of a Spatial Multicriteria Decision Analysis for Urban Development in Ulaanbaatar, Mongolia. Math. Probl. Eng. Volume 2017. 2017. Article ID 2819795.

10. Bailang Yua.; Hongxing Liub.; Jianping Wua.; Yingjie Hua.; Li Zhanga. Automated derivation of urban building density information using airborne LiDAR data and object-based method. Landscape and Urban Planning. 2010, 98, 210-219.

11. Xian-Zhang Pan.; Qi-Guo Zhao.; Jie Chen.; Yin Liang and Bo, Sun. Analyzing the Variation of Building Density Using High Spatial Resolution Satellite Images: the Example of Shanghai City. Sensors. 2008, 8, 2541-2550.

12. Cao Wei.; Zhou Shenglu.; Wu Shaohua. Measuring Smart Land Use in Urban-Rural Regions of China: A Case Study of Pukou, Nanjing City. Growth and Change, Volume 49, Issue1. 2018, 189-202.

13. Chen, L.D.; Fu, B.J. Analysis of impact of human activity on landscape structure in Yellow River Delta: A case study of Dong Ying region. Acta Ecologica Sinica. 16(4). 1996, 337-344.

14. Xiao, D.N.; Li, X.Y.; Song, D.M. Landscape changes and ecological reconstruction in Minqin Huqu oasis. Acta Ecologica Sinica. 25(10). 2005, 2478-2483.

15. Addison, P.S. Fractals and Chaos: An Illustrated Course; Institute of Physics Publishing: Bristol, U.K, 1997.

16. Peitgen, H.O.; Jürgens, H.; Saupe, D. Chaos and Fractals. Springer. 2004, 192-209.

17. Mandelbrot, B. The Fractal Geometry of Nature; Freeman: San Francisco, CA, USA, 1983.

18. Fatih Terzi; H Serdar Kaya. Dynamic spatial analysis of urban sprawl through fractal geometry: the case of Istanbul. Environment and Planning B: Planning and Design. 2011, 38, 175-190.

19. Taylor, R.; Newell, B.; Spehar, B.; Clifford, C. Fractals: A Resonance between Art and Nature. Mathematics and Culture. 2005, 53-63.

20. Torrens, P.M.; Alberti, M. Measuring Sprawl, Paper 27; Centre for Advanced Spatial Analysis: London, UK, 2000. 
21. Kaye, B.H. A Random Walk through Fractal Dimensions; VCH Publishers: New York, USA, 1989.

22. Batty, M.; Longley, P.A. The Fractal Simulation of Urban Structure. Environmental and Planning A: Economy and Space, 1986, 18, 1143-1179.

23. Fan, W.; Shi, Y.; Liu, Y. Application of GIS in quantifying the urban form: A case study of Shanghai. Journal of Digital Content Technology and its Applications 6 (23). 2012, 344-353.

24. Ritter, C.; Heyde, M.; Schwarz, U. D.; Rademann, K. Controlled translational manipulation of small latex spheres by dynamic force microscopy. Langmuir, 2002, 18, 7798-7803.

25. Richardson, L.F. A note: Measuring compactness as a requirement of legislative apportionment. Mid-west Journal of Political Science, 1961, 5, 70-74.

26. Sun, J.; Huang, Z.; Southworth, J.; Qie, Y. Mapping fractality during the process of deforestation in an Amazon tri-national frontier. Remote Sensing Letters. 2013, 589-598.

27. Abdullahi, S.; Pradhan B. Urban Compactness Assessment. Spatial Modeling and Assessment of Urban Form. Springer. 2017, 93-137.

28. Çalışkan, O. Urban compactness: A Study of Ankara Urban Form; MsC thesis: Middle east technical university, Ankara, Turkey, 2004.

29. Dantzig, G.B.; Satty, T. L. Compact City : A Plan for a Livable Urban Environment; W.H.Freeman: 1974.

30. Kaji, H.; Kanegae, H.; Ishibashi, K.; Hara, N. Compact city and developing countries; The Open Meeting of the Global Environmental Change Research Community: Montreal, Canada, 2003.

31. Doebele, W.A. Land Readjustment: A Different Approach to Financing Urbanization; Lexington Books: Boston, USA, 1982.

32. Dunkerley, H.B. Urban Land Policy: Issues and Opportunities; AWorld Bank Publication, Oxford University Press: 1983.

33. Kitay, G. M. Land Acquisition in Developing Countries: Policies and Procedures of the Public Sector; Lincoln Institute of LandPolicy: Boston, USA,1985.

34. Yomralioglu, T. (1992). Determination of Land Parcel Values in Land Reallocation using GIS, Proc. International Congress on Agrarian Reform and Rural Development: Ankara, Turkey, 1992, 403-411.

35. Muller, J.R. Detailed District Plan and Land Readjustment Project, In session 5: Land Policies and Management for Urban Development; International Conference on Urban Development Policies and Projects: Nagoya, Japan, 1992. 